University of Nebraska - Lincoln

DigitalCommons@University of Nebraska - Lincoln

\title{
Kinematic and electromyographic analyses of normal and device- assisted sit-to-stand transfers
}

Judith M. Burnfield

Madonna Rehabilitation Hospital, jburnfield@madonna.org

Yu Shu

Madonna Rehabilitation Hospital

Thad W. Buster

Madonna Rehabilitation Hospital

Adam P. Taylor

Madonna Rehabilitation Hospital

Michaela M. McBride

US Army Research Laboratory Human Research Engineering Directorate

See next page for additional authors

Follow this and additional works at: https://digitalcommons.unl.edu/usarmyresearch

Burnfield, Judith M.; Shu, Yu; Buster, Thad W.; Taylor, Adam P.; McBride, Michaela M.; and Krause, Megan E., "Kinematic and electromyographic analyses of normal and device-assisted sit-to-stand transfers" (2012). US Army Research. 187.

https://digitalcommons.unl.edu/usarmyresearch/187

This Article is brought to you for free and open access by the U.S. Department of Defense at DigitalCommons@University of Nebraska - Lincoln. It has been accepted for inclusion in US Army Research by an authorized administrator of DigitalCommons@University of Nebraska - Lincoln. 


\section{Authors}

Judith M. Burnfield, Yu Shu, Thad W. Buster, Adam P. Taylor, Michaela M. McBride, and Megan E. Krause 


\title{
Kinematic and electromyographic analyses of normal and device-assisted sit-to-stand transfers
}

\author{
Judith M. Burnfield ${ }^{\mathrm{a}, *}$, Yu Shu ${ }^{\mathrm{a}}$, Thad W. Buster ${ }^{\mathrm{a}}$, Adam P. Taylor ${ }^{\mathrm{a}}$, Michaela M. McBride ${ }^{\mathrm{b}}$, \\ Megan E. Krause ${ }^{c}$ \\ ${ }^{a}$ Institute for Rehabilitation Science and Engineering, Madonna Rehabilitation Hospital, 5401 South Street, Lincoln, NE 68506, United States \\ ${ }^{\mathrm{b}}$ US Army Research Laboratory Human Research Engineering Directorate, 2800 Powder Mill Road, Adelphi, MD 20783, United States \\ ${ }^{\mathrm{c}}$ University of Michigan Orthotics \& Prosthetics Center, 2850 S. Industrial Hwy, Ste 400, Ann Arbor, MI 48104, United States
}

\section{A R T I C L E I N F O}

\section{Article history:}

Received 5 August 2011

Received in revised form 3 May 2012

Accepted 7 May 2012

\section{Keywords:}

Rehabilitation

Safe patient handling

Physical therapy

Arisk factors

Occupational injury

\begin{abstract}
A B S T R A C T
Mechanical sit-to-stand devices assist patient transfers and help protect against work-related injuries in rehabilitation environments. However, observational differences between patient's movements within devices compared to normal sit-to-stand transfers deter clinician use. This study compared kinematics and muscle demands during sit-to-stand transfers with no device (ND), and device-assisted during which participants exerted no effort (DA-NE) and best effort (DA-BE). Coefficient of multiple correlations (CMCs) compared kinematic profiles during each device-assisted condition to ND. Compared to DA-NE, CMCs were higher during DA-BE at the hip, knee, and ankle. However, DA-BE values were lower than DA$\mathrm{NE}$ at the trunk and pelvis due to the device's mechanical constraints. In general, all joints' final DA-NE postures were more flexed than other conditions. Electromyographic was significantly lower during DANE compared to ND for all muscles except lateral hamstring, and during DA-BE compared to ND for gluteus maximus, gastrocnemius, and soleus. Verbal encouragement (DA-BE) significantly increased medial hamstring, vastus lateralis, gastrocnemius, soleus and tibialis anterior activation compared to DA-NE. In conclusion, device-assisted sit-to-stand movements differed from normal sit-to-stand patterns. Verbally encouraging best effort during device-assisted transfers elevated select lower extremity muscle activation and led to greater similarity in hip, knee and ankle movement profiles. However, trunk and pelvis profiles declined.
\end{abstract}

(c) 2012 Elsevier B.V. All rights reserved.

\section{Introduction}

Workplace injuries are prevalent in healthcare [1-10]. Among nursing home employees, incidence rates for back injuries resulting in lost work days are more than twice construction workers' rates and over three times agricultural workers' rates [16]. A significant number of clinicians' injuries result from lifting and transferring patients [11]. Physical therapists performing 6-10 patient transfers a day are 2.4 times more likely to experience low back injuries than therapists not performing transfers [12].

The nursing profession's implementation of safe patient handling and movement policies [13] has dramatically reduced work-related injuries [14], chronic pain (23\%) [15], medical expenses (74\%), worker compensation payments (50\%), and estimated restricted duty costs (95\%) [16]. One tool emerging from these initiatives is the battery-powered sit-to-stand transfer device. It safely lifts and lowers patients between seated and

\footnotetext{
* Corresponding author. Tel.: +1 4024839669.

E-mail address: jburnfield@madonna.org (J.M. Burnfield).
}

standing positions, while reducing the risk of caregiver injury $[17,18]$.

Given notable reductions in injuries that have arisen from implementing safe lifting policies in nursing, it is reasonable to expect that therapists would readily incorporate lifting equipment into their routines to reduce injuries. However, therapists have been reluctant to adopt device usage due to concerns regarding therapeutic value [19]. Movement patterns displayed by patients when performing device-assisted transfers observationally differ from normal sit-to-stand transfers. Additionally, traditional approaches to using automated devices often do not encourage patients to try to stand-up, thus may discourage active muscle engagement compared to clinician-assisted transfers. Clinicians' concerns regarding mechanical sit-to-stand devices arise in part from current practice paradigms that emphasize intensive, taskspecific training for promoting recovery of function and cortical reorganization following neurologic injury [20,21].

Given the importance of task specificity to rehabilitation, this study's primary aim was to explore whether kinematic and electromyographic patterns during device-assisted sit-to-stand transfers were similar to unassisted transfers. Individuals without 
known pathology were specifically recruited to isolate the effects of the device's mechanical design from the confounding influence of weakness, balance impairments, and movement control deficits on transfers. Participants were assessed while exerting no purposeful effort to simulate traditional device-assisted sit-tostand transfers performed by patients. Participants also were assessed while attempting to offer their best effort to stand within the device to explore the mechanical constraints imposed by the device. It was hypothesized that compared to sit-to-stand transfers without a device, during device-assisted conditions forward trunk lean would be restricted due to the device's mechanical constraints. Additionally, it was hypothesized that the ankle would show minimal motion during device-assisted sit-tostands because ankle stabilizing mechanisms would constrain dorsiflexion. Finally, it was hypothesized that muscle activity would be greater in key lower extremity extensors when participants were encouraged to use their legs to help stand within the device.

\section{Methods}

\subsection{Participants}

Ten adults ( 5 males), free from musculoskeletal and neurological impairment, were recruited from the local community [mean (SD) age: 21.0 (2.4) years; body mass: $71.9 \mathrm{~kg}$ (10.7); height: $178.2 \mathrm{~cm}(12.2)]$.

\subsection{Instrumentation}

The Qualisys Motion Analysis System and Qualisys Track Manager software (Gothenburg, Sweden) defined three-dimensional motion (12 Oqus Series-3 cameras, sampling rate $120 \mathrm{~Hz}$ ). The MA-300-10 EMG system and MA-411 surface electrodes (Motion Lab Systems, Inc., Baton Rouge, LA) recorded muscle activity. Signals were low-pass filtered $(500 \mathrm{~Hz})$ and digitally recorded $(1200 \mathrm{~Hz})$. Visual 3D software (C-Motion, Inc., Germantown, MD) performed signal processing.

A Vera-lift sit-to-stand device (Model V350, Vancare Inc., Aurora, NE) was used (Fig. 1). It included a rotation arm (54 cm long) capable of elevating a body sling from $111 \mathrm{~cm}$ to $173 \mathrm{~cm}$ above the floor and a foot platform $(43 \mathrm{~cm}$ by $32 \mathrm{~cm}$ ) located $\sim 11 \mathrm{~cm}$ above floor level and tilted $\sim 8^{\circ}$ upward (heel to toe). Velcro strapping secured participants' lower legs to dense foam $(\sim 46 \mathrm{~cm}$ by $16 \mathrm{~cm})$ to prevent knee collapse during transfers.

\subsection{Procedure}

Testing was performed in Madonna Rehabilitation Hospital's (MRH's) Movement and Neurosciences Center after participants signed an informed consent approved by MRH's Institutional Review Board.

EMG electrodes were secured over muscle bellies of the right limb's gluteus maximus, gluteus medius, vastus lateralis, medial hamstring, lateral hamstring tibialis anterior, medial gastrocnemius and soleus using standard techniques $[22,23]$. Inspection of real-time EMG signals during specific resisted movements validated electrode placement. Following practice, a 5-s EMG signal was recorded during maximum isometric manual muscle testing of each muscle using standard tests [24]. Then a 5-s resting EMG trial was recorded.

Reflective markers were placed bilaterally over the acromion processes, iliac crests, posterior superior iliac spines (PSIS), anterior superior iliac spines, and the right lower extremity's greater trochanter, medial and lateral femoral condyles, bilateral medial and lateral malleoli, posterior heels, medial first metatarsal head (MTH), between distal second and third MTHs, distal lateral fifth MTH, and midfoot's lateral border [25]. Twelve tracking marker clusters were secured on the trunk, thighs and shanks [26]. A static calibration trial was recorded to define the 16-segment model.

Kinematics and EMG were recorded simultaneously while participants performed the following (three times, random order):

1. No device (ND): sit-to-stand without device (participants' self-selected seating posture and foot stance). Instructed, "Beginning in a seated position, please stand up at your normal comfortable speed."

2. Device-assisted-best effort (DA-BE): instructed, "We would like you to stand up with the device. Use your legs to stand up as best you can within the device. Please do not use your arms to lift your body. We will use a remote control to control the device as it lifts your body."

3. Device-assisted-no effort (DA-NE): instructed, "We would like you to let the device lift your entire body weight. Do not assist the device. Lean back into the sling so it can support your whole body weight. We will use a remote control to control the device as it lifts your body."
Participants started seated on a backless and armless chair (18 in. height). In no device trials, participants moved at a self-selected speed. During device-assisted trials, the device's default speed was used.

\subsection{Data analysis}

\subsubsection{Onset and cessation}

Left PSIS marker data defined and normalized movement cycles. Onset, or zero percent movement cycle $(0 \% \mathrm{MC})$, was defined as the frame at which the PSIS marker's location increased vertically more than three standard deviations from the first 100 frames' average prior to motion initiation. Cessation (100\% MC) was defined as the frame at which the marker reached maximum anterior position.

\subsubsection{Kinematics}

Visual 3D was used to produce a 3-dimensional trajectory for each marker and for filtering (6-Hz Butterworth low-pass digital). The position and orientation of trunk, pelvis, thigh, shank and foot segments were obtained and lower extremity joint angles calculated for each \%MC. Sagittal plane trunk and pelvis orientations were expressed relative to vertical while hip, knee and ankle angles were generated by their relative segments. Separate ensemble averaged joint angle plots were created for each participant and condition, and start, end and peak joint angles were identified. Three group ensemble averaged profiles (ND, DA-BE and DA-NE) were created for each joint angle by combining all participants' data.

\subsubsection{Electromyography}

One participant's gluteus maximus data were excluded from analysis due to electrode failure. After adjusting for DC bias and baseline noise, EMG data were digitally filtered ( $60 \mathrm{~Hz}$ notch, $10 \mathrm{~Hz}$ high-pass and $350 \mathrm{~Hz}$ low-pass Butterworth), full-wave rectified, and integrated over $0.01 \mathrm{~s}$ intervals. EMG timing, duration, and amplitude were calculated using Visual 3D software and intensities (peak, mean) were normalized and reported as a percentage of the maximal isometric manual muscle test (\%MMT). Onsets and cessations were determined for all EMG envelopes exceeding 5\% MMT amplitude [27,28]. EMG envelopes separated by short gaps $(<50 \mathrm{~ms})$ were combined into larger packets for duration calculations (expressed as \%MC). A time-normalized mean profile for each participant and muscle was created for each condition.

\subsection{Statistical analysis}

Separate one-way analyses of variance with repeated measures identified significant differences in kinematic and EMG variables between ND, DA-BE and DANE. When normality assumptions were violated, Friedman's ANOVA on ranks identified significant differences. Bonferroni adjustments accounted for multiple comparisons within kinematic $(p<0.01)$ and EMG variable families $(p<0.006)$. Coefficients of multiple correlations (CMC) [29] were calculated to quantify similarity in movement patterns of DA-BE and DA-NE to ND for each joint.

\section{Results}

\subsection{Kinematics}

Compared to ND, device-assisted conditions (i.e., feet supported on platform) resulted in significantly narrower heel-to-heel $(\mathrm{ND}=24 \mathrm{~cm}$ vs. $\mathrm{DA}-\mathrm{BE}=18 \mathrm{~cm}, \mathrm{DA}-\mathrm{NE}=17 \mathrm{~cm} ; p<0.001)$ and toe-to-toe $(\mathrm{ND}=35 \mathrm{~cm} \quad$ vs. $\mathrm{DA}-\mathrm{BE}=26 \mathrm{~cm}, \quad \mathrm{DA}-\mathrm{NE}=27 \mathrm{~cm}$; $p<0.001)$ distances.

Compared to DA-NE, CMC values were higher during DA-BE at the hip ( 0.87 vs. 0.77 ), knee ( 0.95 vs. 0.86 ), and ankle ( 0.69 vs. 0.58 ; Fig. 2). In contrast, DA-BE values were substantially lower than DA$\mathrm{NE}$ at the trunk ( 0.49 vs. 0.56$)$ and pelvis ( 0.35 vs. 0.75$)$.

In general, the final DA-NE joint postures were more flexed than the other two conditions (Table 1 and Fig. 2). Trunk flexion was less during DA-BE compared to ND at each epoch (start, peak, end). Progressive trunk extension during DA-NE and subtle trunk flexion during DA-NE contrasted sharply with ND's characteristic flexion wave. Peak trunk flexion timing varied notably between ND $(38 \%$ MC) and DA-NE (95\% MC). Participants ended in significantly greater trunk flexion during DA-NE than ND, and both exceeded that recorded during $\mathrm{DA}-\mathrm{BE}$.

The pelvis started in significantly greater posterior tilt during both device-assisted conditions compared to ND. While peak anterior tilt did not differ significantly between DA-NE and ND, the peak's timing was notably delayed for DA-NE (99\% MC) compared 
Start
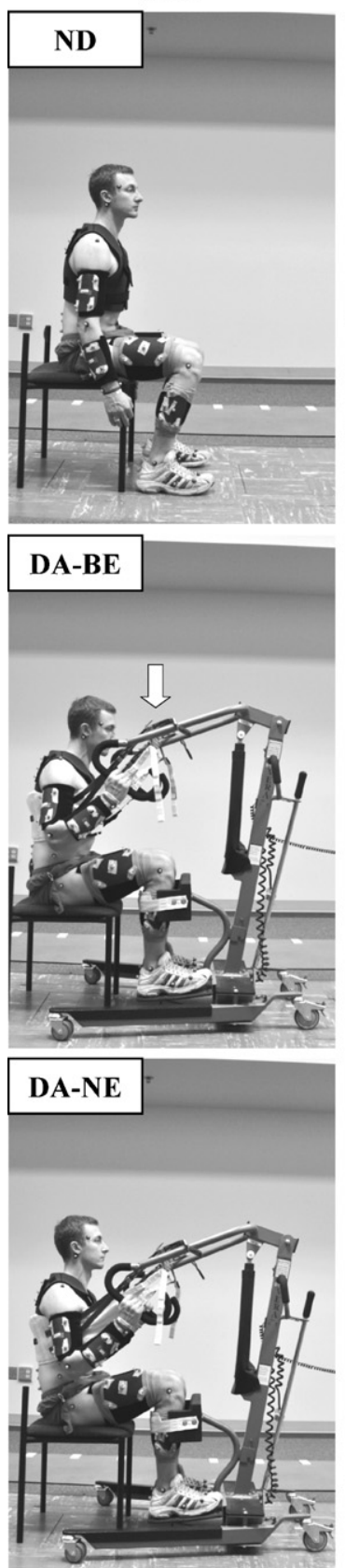

Mid
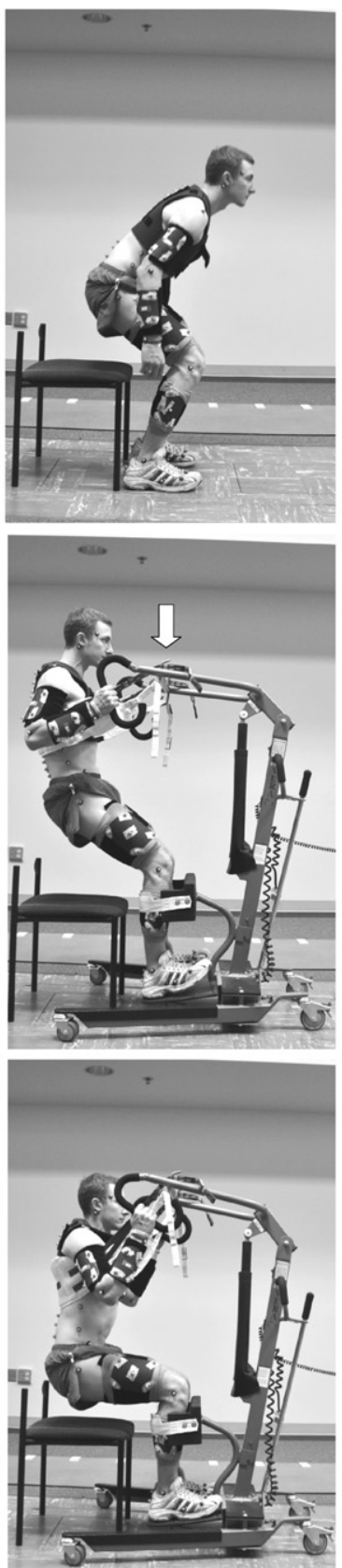

End
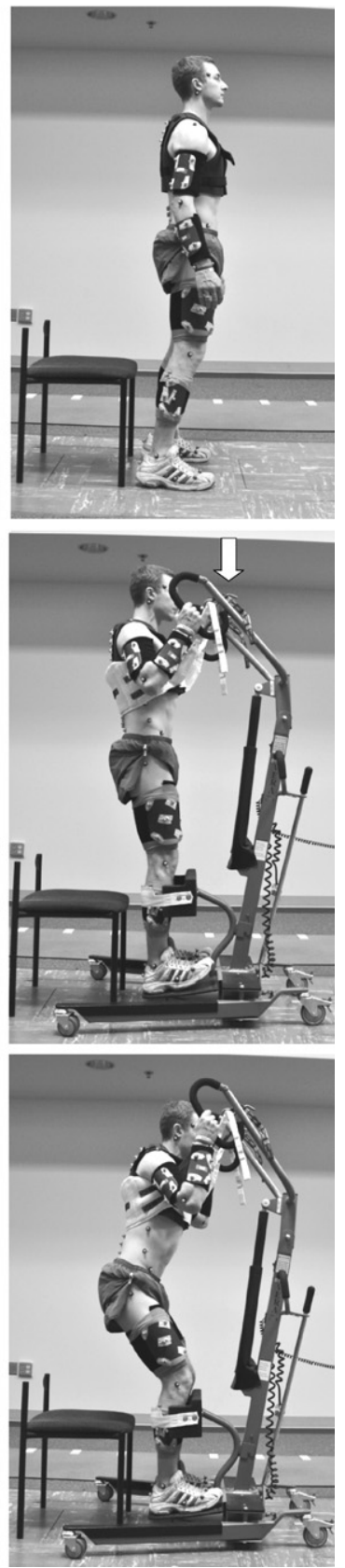

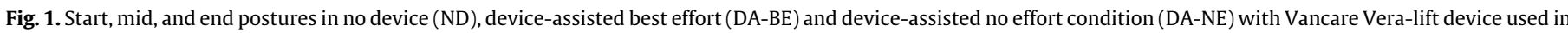
the current study. The white arrow points to the location of the cross bar.

to ND (46\% MC). Peak anterior tilt was notably less during DA-BE than the other conditions. The pelvis' end posture mimicked the pattern displayed at the trunk.

The hip's and knee's starting position did not differ significantly across conditions. However, at the movement cycle's end, the hip and knee were more flexed during DA-NE than the other conditions. Lack of the characteristic hip flexion wave during DA-BE significantly reduced peak flexion compared to the other conditions.

While ankle dorsiflexion did not differ significantly across conditions at the MC's start, significantly higher peak values were recorded during $\mathrm{ND}\left(26.8^{\circ}\right)$ compared to DA-NE $\left(21.2^{\circ}\right)$ and DA-BE $\left(20.0^{\circ}\right)$. In contrast, dorsiflexion was significantly less at the movement cycle's end during ND $\left(6.1^{\circ}\right)$ compared to DA-NE $\left(21.0^{\circ}\right)$ and $\mathrm{DA}-\mathrm{BE}\left(16.5^{\circ}\right)$, reflecting restricted ankle motion during device-assisted conditions compared to ND.

\subsection{Electromyography}

Except for lateral hamstrings, EMG activation was markedly and significantly lower during DA-NE compared to ND for all muscles (72-99\% decreased peak across muscles; 78-99.9\% decreased duration), and during DA-BE compared to ND for gluteus maximus, gastrocnemius, and soleus (34-62\% decreased peak across muscles; 45-78\% decreased duration; Table 2 and Fig. 3). While lower EMG amplitudes also were recorded in vastus lateralis and tibialis anterior during DA-BE compared to ND, the durations were longer. Verbal encouragement (DA-BE) resulted in 

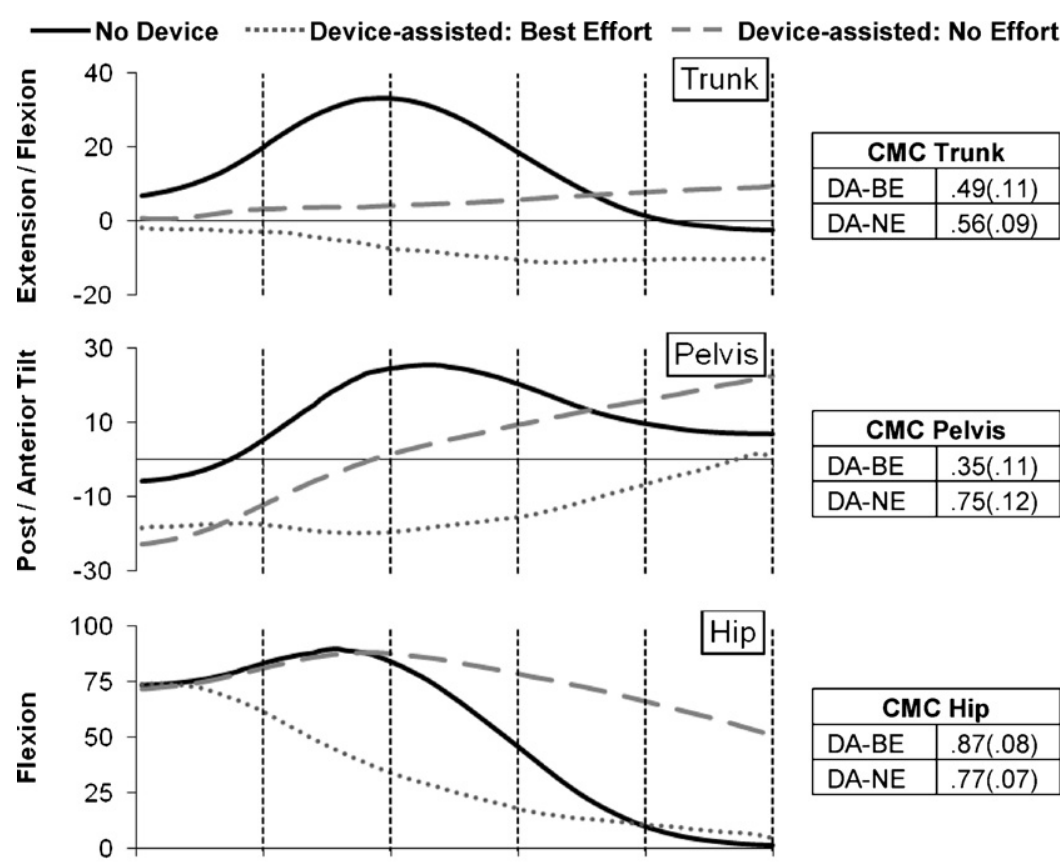

\begin{tabular}{|l|l|}
\hline \multicolumn{2}{|c}{ CMC Hip } \\
\hline DA-BE & $.87(.08)$ \\
\hline DA-NE & $.77(.07)$ \\
\hline
\end{tabular}

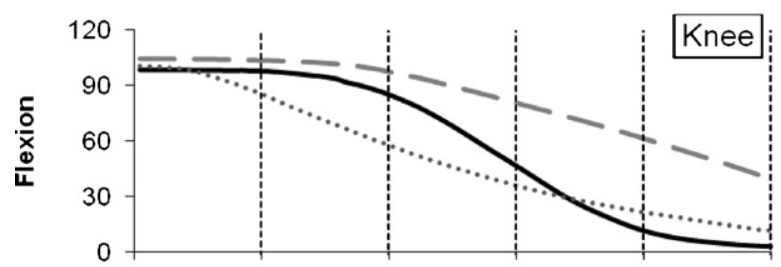

CMC Knee

\begin{tabular}{|l|l|}
\hline DA-BE & $.95(.03)$ \\
\hline
\end{tabular}

\begin{tabular}{l|l|l|l}
\hline DA-NE & $.86(.07)$ \\
\hline
\end{tabular}

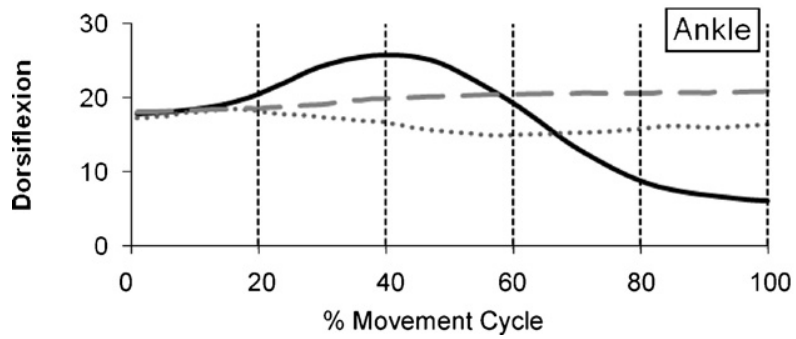

\begin{tabular}{|l|l|}
\hline \multicolumn{2}{|c|}{ CMC Ankle } \\
\hline DA-BE & $.69(.11)$ \\
\hline DA-NE & $.58(.10)$ \\
\hline
\end{tabular}

Fig. 2. Ensemble averaged $(n=10)$ sagittal plane mean joint motion $\left(^{\circ}\right)$ of the trunk, pelvis, hip, knee, and ankle recorded during sit-to-stand transfers with no device (ND; solid), device-assisted best effort (DA-BE; dotted), and device-assisted no effort (DA-NE; dashed) conditions. High coefficient of multiple correlation (CMC) values at the hip and knee of the DA-BE condition reflect the high similarities between DA-BE and ND at these segments. In contrast, low CMC values at the trunk, pelvis, and ankle during DA$\mathrm{BE}$ show the high variance comparing ND and DA-BE at these joints.

Table 1

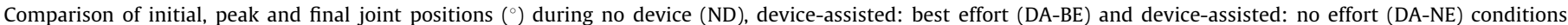
(mean \pm standard deviation).

\begin{tabular}{|c|c|c|c|c|c|}
\hline Joint & Phase & No device & Device-assisted: best effort & Device-assisted: no effort & Significant main effect $(p<0.01)$ \\
\hline \multirow[t]{3}{*}{ Trunk $(n=10)$} & Start & $6.9 \pm 6.2$ & $-1.7 \pm 10.1$ & $0.7 \pm 12.4$ & $\mathrm{ND}>\mathrm{DA}-\mathrm{BE}$ \\
\hline & Peak & $36.2 \pm 6.9$ & $-0.4 \pm 9.3$ & $11.5 \pm 7.1$ & $\mathrm{ND}>\mathrm{DA}-\mathrm{BE}$ \\
\hline & End & $-2.4 \pm 5.3$ & $-10.7 \pm 7.6$ & $9.5 \pm 6.1$ & $\mathrm{DA}-\mathrm{NE}>\mathrm{ND}>\mathrm{DA}-\mathrm{BE}$ \\
\hline \multirow[t]{3}{*}{ Pelvis $(n=10)$} & Start & $-5.7 \pm 7.6$ & $-18.4 \pm 10.6$ & $-22.8 \pm 7.9$ & $\mathrm{ND}>\mathrm{DA}-\mathrm{BE}, \mathrm{DA}-\mathrm{NE}$ \\
\hline & Peak & $28.1 \pm 7.0$ & $1.6 \pm 6.8$ & $22.8 \pm 8.4$ & ND, DA-NE $>$ DA-BE \\
\hline & End & $7.1 \pm 6.9$ & $0.9 \pm 7.1$ & $22.7 \pm 8.5$ & $\mathrm{DA}-\mathrm{NE}>\mathrm{ND}>\mathrm{DA}-\mathrm{BE}$ \\
\hline \multirow[t]{3}{*}{ Hip $(n=10)$} & Start & $73.6 \pm 10.0$ & $73.8 \pm 12.6$ & $72.0 \pm 11.1$ & NS $(p=0.571)$ \\
\hline & Peak & $93.0 \pm 9.5$ & $75.1 \pm 12.3$ & $89.6 \pm 9.4$ & $\mathrm{ND}, \mathrm{DA}-\mathrm{NE}>\mathrm{DA}-\mathrm{BE}$ \\
\hline & End & $1.7 \pm 7.8$ & $4.5 \pm 9.5$ & $51.5 \pm 11.7$ & $\mathrm{DA}-\mathrm{NE}>\mathrm{DA}-\mathrm{BE}, \mathrm{ND}$ \\
\hline \multirow[t]{3}{*}{ Knee $(n=10)$} & Start & $98.4 \pm 10.0$ & $100.6 \pm 12.9$ & $104.2 \pm 11.3$ & NS $(p=0.131)$ \\
\hline & Peak & $98.7 \pm 9.8$ & $101.3 \pm 11.5$ & $104.4 \pm 11.3$ & NS $(p=0.095)$ \\
\hline & End & $2.8 \pm 6.7$ & $11.8 \pm 12.8$ & $40.5 \pm 12.2$ & $\mathrm{DA}-\mathrm{NE}>\mathrm{DA}-\mathrm{BE}>\mathrm{ND}$ \\
\hline \multirow[t]{3}{*}{ Ankle $(n=10)$} & Start & $17.8 \pm 6.2$ & $17.3 \pm 2.8$ & $18.2 \pm 4.1$ & NS $(p=0.909)$ \\
\hline & Peak & $26.8 \pm 4.8$ & $20.0 \pm 3.9$ & $21.2 \pm 4.3$ & $\mathrm{ND}>\mathrm{DA}-\mathrm{NE}, \mathrm{DA}-\mathrm{BE}$ \\
\hline & End & $6.1 \pm 4.2$ & $16.5 \pm 3.7$ & $21.0 \pm 4.5$ & $\mathrm{DA}-\mathrm{NE}>\mathrm{DA}-\mathrm{BE}>\mathrm{ND}$ \\
\hline
\end{tabular}

NS = not significant 
Table 2

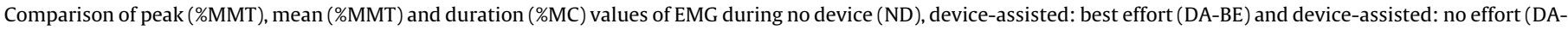
$\mathrm{NE})$ conditions (mean \pm standard deviation).

\begin{tabular}{|c|c|c|c|c|c|}
\hline Muscle & & No device & Device-assisted: best effort & Device-assisted: no effort & Significant main effects $(p<0.006)$ \\
\hline \multirow[t]{3}{*}{ Gluteus maximus $(n=9)$} & Peak & $21 \pm 11$ & $8 \pm 5$ & $4 \pm 4$ & $\mathrm{ND}>\mathrm{DA}-\mathrm{BE}, \mathrm{DA}-\mathrm{NE}$ \\
\hline & Mean & $10 \pm 4$ & $3 \pm 3$ & $2 \pm 2$ & $\mathrm{ND}>\mathrm{DA}-\mathrm{BE}, \mathrm{DA}-\mathrm{NE}$ \\
\hline & Duration & $37 \pm 20$ & $8 \pm 8$ & $5 \pm 14$ & $\mathrm{ND}>\mathrm{DA}-\mathrm{BE}, \mathrm{DA}-\mathrm{NE}$ \\
\hline \multirow[t]{3}{*}{ Gluteus medius $(n=10)$} & Peak & $11 \pm 10$ & $9 \pm 8$ & $1 \pm 1$ & $\mathrm{ND}>\mathrm{DA}-\mathrm{NE}$ \\
\hline & Mean & $5 \pm 5$ & $4 \pm 3$ & $0.2 \pm 0.6$ & $\mathrm{ND}>\mathrm{DA}-\mathrm{NE}$ \\
\hline & Duration & $14 \pm 13$ & $8 \pm 15$ & $0.02 \pm 0.07$ & $\mathrm{ND}>\mathrm{DA}-\mathrm{NE}$ \\
\hline \multirow[t]{3}{*}{ Lateral hamstring $(n=10)$} & Peak & $14 \pm 12$ & $11 \pm 13$ & $4 \pm 4$ & NS $(p=0.06)$ \\
\hline & Mean & $7 \pm 6$ & $4 \pm 5$ & $2 \pm 3$ & NS $(p=0.03)$ \\
\hline & Duration & $22 \pm 22$ & $20 \pm 35$ & $5 \pm 10$ & NS $(p=0.15)$ \\
\hline \multirow[t]{3}{*}{ Medial hamstring $(n=10)$} & Peak & $15 \pm 16$ & $15 \pm 12$ & $4 \pm 4$ & DA-BE, ND > DA-NE \\
\hline & Mean & $7 \pm 5$ & $6 \pm 4$ & $2 \pm 3$ & $\mathrm{ND}, \mathrm{DA}-\mathrm{BE}>\mathrm{DA}-\mathrm{NE}$ \\
\hline & Duration & $27 \pm 28$ & $28 \pm 26$ & $5 \pm 12$ & DA-BE, ND > DA-NE \\
\hline \multirow[t]{3}{*}{ Vastus lateralis $(n=10)$} & Peak & $63 \pm 24$ & $48 \pm 12$ & $2 \pm 2$ & $\mathrm{ND}, \mathrm{DA}-\mathrm{BE}>\mathrm{DA}-\mathrm{NE}$ \\
\hline & Mean & $26 \pm 9$ & $20 \pm 5$ & $1 \pm 2$ & $\mathrm{ND}>\mathrm{DA}-\mathrm{BE}>\mathrm{DA}-\mathrm{NE}$ \\
\hline & Duration & $68 \pm 10$ & $87 \pm 15$ & $1 \pm 3$ & $\mathrm{DA}-\mathrm{BE}>\mathrm{ND}>\mathrm{DA}-\mathrm{NE}$ \\
\hline \multirow[t]{3}{*}{ Gastrocnemius $(n=10)$} & Peak & $17 \pm 4$ & $11 \pm 6$ & $2 \pm 3$ & $\mathrm{ND}>\mathrm{DA}-\mathrm{BE}>\mathrm{DA}-\mathrm{NE}$ \\
\hline & Mean & $8 \pm 2$ & $5 \pm 2$ & $1 \pm 2$ & $\mathrm{ND}>\mathrm{DA}-\mathrm{BE}>\mathrm{DA}-\mathrm{NE}$ \\
\hline & Duration & $37 \pm 13$ & $10 \pm 10$ & $0.2 \pm 0.4$ & $\mathrm{ND}>\mathrm{DA}-\mathrm{BE}, \mathrm{DA}-\mathrm{NE}$ \\
\hline \multirow[t]{3}{*}{ Soleus $(n=10)$} & Peak & $42 \pm 24$ & $16 \pm 7$ & $1 \pm 1$ & $\mathrm{ND}>\mathrm{DA}-\mathrm{BE}, \mathrm{DA}-\mathrm{NE}$ \\
\hline & Mean & $17 \pm 8$ & $6 \pm 3$ & $1 \pm 1$ & $\mathrm{ND}>\mathrm{DA}-\mathrm{BE}, \mathrm{DA}-\mathrm{NE}$ \\
\hline & Duration & $62 \pm 20$ & $34 \pm 27$ & $0.05 \pm 0.1$ & $\mathrm{ND}>\mathrm{DA}-\mathrm{BE}>\mathrm{DA}-\mathrm{NE}$ \\
\hline \multirow[t]{3}{*}{ Tibialis anterior $(n=10)$} & Peak & $85 \pm 40$ & $53 \pm 41$ & $1 \pm 1$ & $\mathrm{ND}>\mathrm{DA}-\mathrm{BE}>\mathrm{DA}-\mathrm{NE}$ \\
\hline & Mean & $34 \pm 17$ & $24 \pm 20$ & $0.3 \pm 1$ & ND, DA-BE > DA-NE \\
\hline & Duration & $48 \pm 12$ & $68 \pm 25$ & $0.04 \pm 0.1$ & $\mathrm{DA}-\mathrm{BE}>\mathrm{ND}>\mathrm{DA}-\mathrm{NE}$ \\
\hline
\end{tabular}

NS = not significant
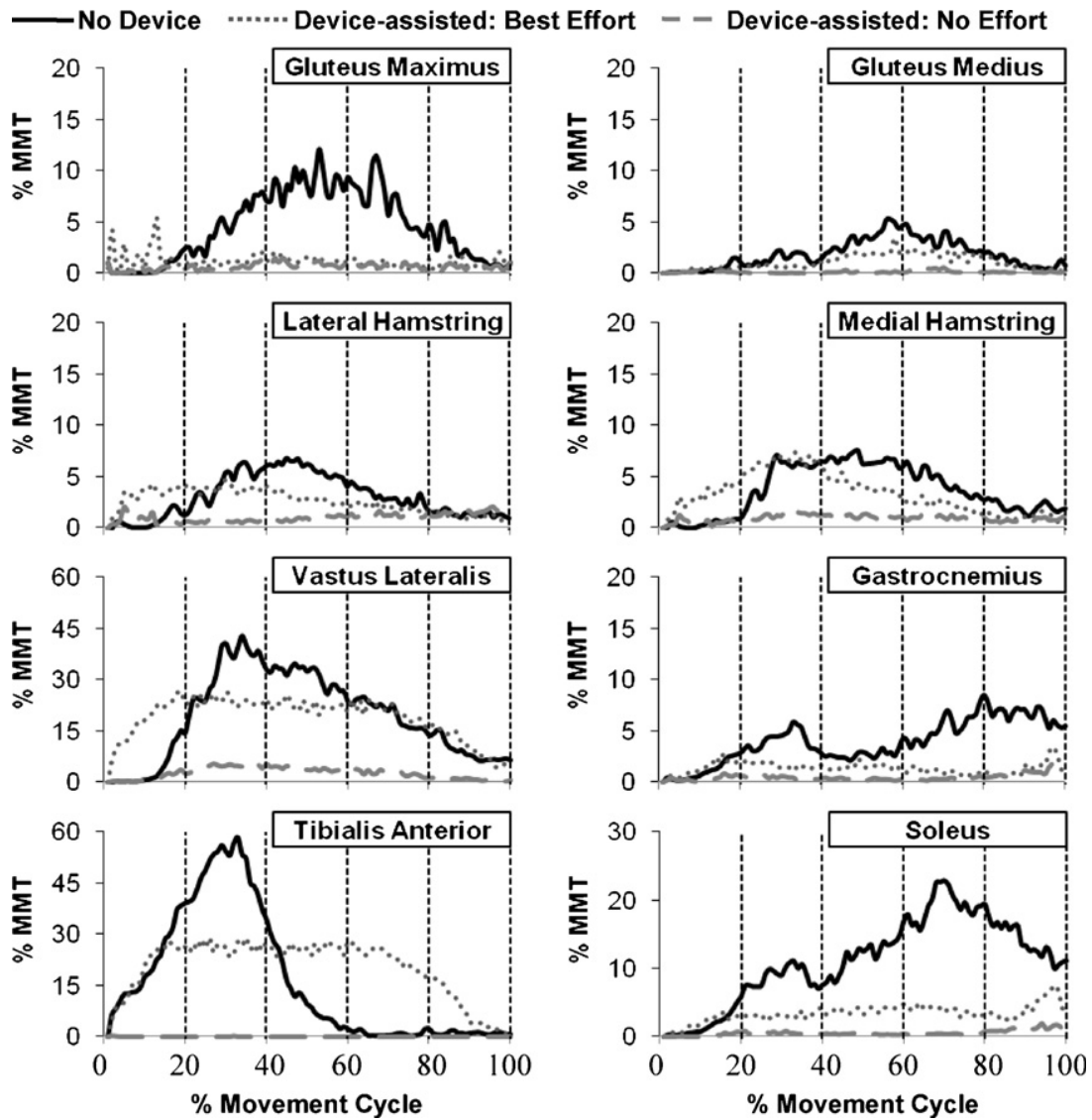

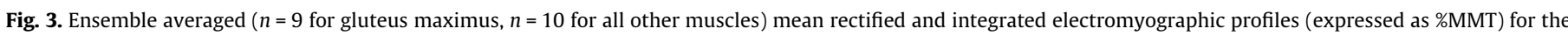

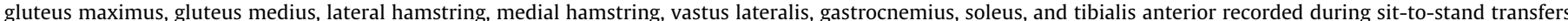

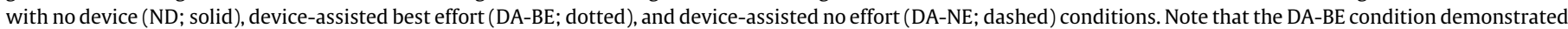
significantly higher muscle activity compared to DA-NE at the gluteus maximus, gluteus medius, vastus lateralis, gastrocnemius, and soleus. 
significantly greater medial hamstring, vastus lateralis, gastrocnemius, soleus and tibialis anterior activation compared to DA-NE.

\section{Discussion}

Relearning to transfer is a key rehabilitation goal for many individuals. When profound weakness and balance deficits prevent patients from safely performing the task, external human and/or device assistance is often required. Device-assisted movement patterns that simulate normal transfers could enable patients to transfer safely while also practicing an activity they seek to relearn.

In the current study, the lift device transferred participants to a standing position with only negligible physical exertion by participants and clinician. Each muscle's average peak EMG activation was less than 5\% MMT during DA-NE. After securing the sling and leg cuff, the clinician only needed to push a button to elevate the participant. However, the device visibly changed participants' movements compared to normal sit-to-stand transfers, particularly trunk and ankle.

As hypothesized, the lifting device restricted normal trunk flexion that occurs when transferring sit-to-stand. As illustrated in Figs. 1 and 2, during ND participants shifted their trunk forward $\left(36.2^{\circ}\right)$ over their feet to stand because the ground provided the only external support. In contrast, during DA-NE, the device's sling supported participants. Peak trunk flexion $\left(11.5^{\circ}\right)$ occurred too late in the movement cycle (95\% MC) to assist with functionally meaningful advancement of body mass over the feet, and the amplitude was less than one-third of that occurring during ND. The hip's excessive flexion $\left(50^{\circ}\right)$ during this same period in the DA-NE movement cycle resulted in the trunk being postured behind the feet. Even during DA-BE, participants failed to advance their trunk over their feet, suggesting the device's constraints (e.g., crossbar located anterior to participant's head) prohibited forward flexion. Participant's interpretation of the instructions '. . .use your legs to stand up best as you can within the device...' also may have contributed to the movement strategy.

Consistent with our second hypothesis, ankle movement during device-assisted conditions was constrained by the manufacturers' ankle strapping mechanism. The ankle angle during deviceassisted transfers varied only $3-4^{\circ}$ across the movement cycle, much less than the $20.7^{\circ}$ dorsiflexion arc recorded during ND. While the strapping was intended to prevent knee collapse, it unfortunately limited the ankle mobility required to advance the body over the base of support during a normal transfer.

The narrow foot platform and Velcro straps securing the lower legs resulted in participants placing their feet closer together during device-assisted conditions compared to self-selected starting posture during ND. Given previous research demonstrating that foot placement affects lower extremity muscle activation patterns during ND sit-to-stand transfers [30], it is conceivable that the altered foot positions imposed by the current study's device also influenced our participants' muscle activation patterns. Further research, exploring foot placements that more closely simulate self-selected postures, should elucidate influences on muscle activation during device-assisted.

The DA-BE condition was included to determine if participants without impairments could achieve a more normal movement pattern if encouraged. Analysis of CMC values resulted in contradictory findings (Fig. 2). Compared to DA-NE, CMC values were poorer during DA-BE for participants' trunk and pelvis when referenced to normal sit-to-stand motion profiles (ND). In contrast, CMC values during DA-BE displayed higher similarity than DA-NE to ND at the hip, knee and ankle. Reliance on the sling for external support may have contributed to participants' more extended trunk posture.
The DA-BE condition also was included to explore therapeutic strategies to promote greater muscle activation. While not all extensor muscles increased activity as expected given our third hypothesis, EMG activation of medial hamstrings, vastus lateralis, gastrocnemius, and soleus was greater during DA-BE compared to DA-NE. Gluteus maximus, gluteus medius and lateral hamstring activation levels were at least 2-fold higher during DA-BE compared to DA-NE, however these differences were not statistically significant. It is probable that the trunk's relatively extended posture during DA-BE reduced any notable challenge to the single joint hip extensors. Tibialis anterior also displayed significantly greater activation during DA-BE. Collectively, these findings indicate that encouraging active engagement is an effective strategy for increasing muscle activation within device-assisted transfers. The relatively lower activation amplitude of gluteus maximus, vastus lateralis, gastrocnemius, soleus, and tibialis anterior during DA-BE compared to ND suggests, however, that participants continued to rely partially on the sling to lift and advance their trunk during DA-BE transfers.

The comparatively low CMC values between DA-BE and ND in trunk, pelvis and ankle joints, demonstrated that the mechanical constraints imposed by the lifting device notably changed kinematics during device-assisted transfers. For example, the cross bar located at head level may constrain trunk flexion during device-assisted transfers. Similarly, Velcro strapping securing the shank to the knee support unfortunately limits normal dorsiflexion during transfers. Additionally, support from the sling may reduce the total effort needed to stand, thus muscle activation levels were often lower even when participants were asked to exert best effort. However, the Vancare Vera-lift was the only device tested so far and transfers were performed from only one chair. It is likely that different lifting mechanism designs (e.g., no cross bar to block forward trunk movement) and support surface heights (e.g., simulating bed) may alter users' transfers. Ideally, if deviceassisted movements closely simulate normal sit-to-stand transfers, then the device should be a good design for rehabilitation because it could be used to promote intensive, task-specific training important for recovery of function and cortical reorganization following neurologic injury.

The current study recruited individuals without disabilities in order to explore constraints imposed by the device on a user's movement. Given that individuals with profound impairments could exhibit different movement patterns, future studies comparing patients' movements during clinician-assisted transfers to those occurring during device-assisted transfers are needed. Additionally, assessing changes in response across a series of trials might provide insights into whether participants learn new movement strategies after repeated practice using the device.

Collectively, this information is expected to lead to greater understanding of optimal ways to promote safe patient transfers as well as facilitate relearning of a skill essential to functional independence in the home and community. The benefit of deviceassisted transfers is that they reduce the physical demands placed on clinicians, and thus injury risk [12]. While the kinematics of device-assisted best-effort transfers are not identical to normal sitto-stand transfers, the effort of practicing may still be beneficial in helping build muscle strength and joint flexibility [20]. The current study's findings suggest that clinicians should consider encouraging active patient engagement during device-assisted transfers when clinically feasible.

\section{Acknowledgements}

This work was supported, in part, by Undergraduate Creative Activities and Research Experiences Program and Agricultural Research Division grants from the University of Nebraska-Lincoln. 


\section{Conflict of interest statement}

No conflicts of interest existed for any authors.

\section{References}

[1] Nelson A. State of the science in patient care ergonomics: lessons learned and gaps in knowledge [abstract]. In: Third annual safe patient handling and movement conference; 2003.

[2] Darragh AR, Campo M, King P. Work-related activities associated with injury in occupational and physical therapists. Work 2012;42(3):1-12.

[3] Stubbs DA, Buckle PW, Hudson MP, Rivers PM, Baty D. Backing out: nurse wastage associated with back pain. International Journal of Nursing Studies 1986;23(4):325-36.

[4] Owen BD. The magnitude of low-back problem in nursing. Western Journal of Nursing Research 1989;11(2):234-42.

[5] Owen BD. Preventing injuries using an ergonomic approach. AORN Journal 2000;72(6):1031-6.

[6] Trinkoff AM, Lipscomb JA, Geiger-Brown J, Storr CL, Brady BA. Perceived physical demands and reported musculoskeletal problems in registered nurses. American Journal of Preventive Medicine 2003;24(3):270-5.

[7] Bork BE, Cook TM, Rosecrance JC, Engelhardt KA, Thomason ME, Wauford IJ, et al. Work-related musculoskeletal disorders among physical therapists. Physical Therapy 1996;76(8):827-35.

[8] Glover W. Work-related strain injuries in physiotherapists: prevalence and prevention of musculoskeletal disorders. Physiotherapy 2002;88(6):364-72.

[9] Cromie JE, Robertson VJ, Best MO. Work-related musculoskeletal disorders in physical therapists: prevalence, severity, risks, and responses. Physical Therapy $2000 ; 80(4): 336-51$

[10] Salik Y, Ozcan A. Work-related musculoskeletal disorders: a survey of physical therapists in Izmir-Turkey. BMC Musculoskeletal Disorders 2004;5(1):27.

[11] Schoen DC. Low back pain. Orthopaedic Nursing 2004;23(2):154-7.

[12] Campo M, Weiser S, Koenig KL, Nordin M. Work-related musculoskeletal disorders in physical therapists: a prospective cohort study with 1-year follow-up. Physical Therapy 2008;88(5):608-19.

[13] Sparkes V. Physiotherapy for stroke rehabilitation: a need for evidence-based handling techniques. Physiotherapy 2000;86(7):348-56.

[14] de Castro AB. Handle with care: the American Nurses Association's campaign to address work-related musculoskeletal disorders. Online Journal of Issues in Nursing 2004;9(3).

[15] Peter D. Safe patient handling: a report. Heart Research Associates Inc.; 2006.
[16] Siddharthan K, Nelson A, Tiesman H, Chen F. Cost effectiveness of a multifaceted program for safe patient handling. Advances in Patient Safety 2005;3: 347-58.

[17] Edlich RF, Winters KL, Hudson MA, Britt LD, Long WB. Prevention of disabling back injuries in nurses by the use of mechanical patient lift systems. Journal of Long-Term Effects of Medical Implants 2004;14(6):521-33.

[18] O’Donnell JM, Goode JS, Henker RA, Kelsey S, Bircher N, Peele P, et al. An ergonomic protocol for patient transfer that can be successfully taught using simulation methods. Clinical Simulation in Nursing 2012;8(1):e3-14.

[19] Nelson A, Harwood KJ, Tracey CA, Dunn KL. Myths and facts about safe patient handling in rehabilitation. Rehabilitation Nursing 2008;33(1):10-7.

[20] Boyne P, Israel S, Dunning K. Speed-dependent body weight supported sit-tostand training in chronic stroke: a case series. Journal of Neurologic Physical Therapy 2011;35(4):178-84.

[21] Hubbard IJ, Parsons MW, Neilson C, Carey LM. Task-specific training: evidence for and translation to clinical practice. Occupational Therapy International 2009;16(3-4):175-89.

[22] Hislop HJ, Montgomery J. Daniel's and Worthingham's muscle testing: techniques of manual examination, 6th ed., Philadelphia: W.B. Saunders Company; 1995.

[23] Cram JR, Kasman GS, Holtz J. Introduction to surface electromyography. Gaithersburg, MD: Aspen Publishers Inc.; 1998.

[24] Hislop H, Montgomery J. Daniel and Worthingham's muscle testing. St. Louis, MO: Saunders Elsevier; 2007.

[25] Burnfield JM, Shu Y, Buster TW, Taylor AP. Similarity of joint kinematics and muscle demands between elliptical training and walking: implications for practice. Physical Therapy 2010;90(2):289-305.

[26] Cappozzo A, Cappello A, Della Croce U, Pensalfini F. Surface-marker cluster design criteria for 3-D bone movement reconstruction. IEEE Transactions on Biomedical Engineering 1997;44(12):10.

[27] Bogey RA, Barnes LA, Perry J. Computer algorithms to characterize individual subject EMG profiles during gait. Archives of Physical Medicine and Rehabilitation 1992;73(9):835-41.

[28] Perry J, Bontrager EL, Bogey RA, Gronley JK, Barnes LA. The rancho EMG analyzer: a computerized system for gait analysis. Journal of Biomedical Engineering 1993;15(6):487-96.

[29] Kadaba MP, Ramakrishnan HK, Wootten ME, Gainey J, Gorton G, Cochran GVB. Repeatability of kinematic, kinetic and electromyographic data in normal adult gait. Journal of Orthopaedic Research 1989;7(6):849-60.

[30] Brunt D, Greenberg B, Wankadia S, Trimble MA, Shechtman O. The effect of foot placement on sit to stand in healthy young subjects and patients with hemiplegia. Archives of Physical Medicine and Rehabilitation 2002;83(7):924-9. 